\title{
Space Computation Sciences LeVERAGING Cloud Computing, ARTificial INTELLIGENCE, AND ADVANCED ANALYTICS TO PoWer INNOVATION: A REVIEW REPORT
}

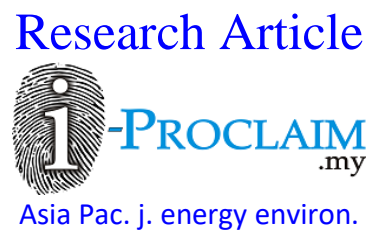

\section{Takudzwa Fadziso}

Institute of Lifelong Learning and Development Studies, Chinhoyi University of Technology, ZIMBABWE

*Email for Correspondence: fadziso.tak@gmail.com

Abstract

In order to realize the goal of exploring and discovering new worlds, technological innovations are important. The space industry has been growing since the first space ship landed on the moon in the Apollo 11 mission. Huge leaps in space technology experienced since then combined with modern technologies such Artificial Intelligence, Data Analytics and Cloud technology can help space explorers to go further in the space and explore territories not reached before, and potentially uncover new space phenomena. The objective of this research is to explore how space computation sciences can leverage Artificial Intelligence, Cloud technologies, and Advanced Data Analysis to power innovations.

Key words

Cloud Computing, Artificial Intelligence, Power Innovation, Space Computation

\section{INTRODUCTION}

Space exploration has been a humankind dream. Curiosity and desire has pushed human's interest into the exploration and discovery of new worlds, leading to the expansion of scientific and technical knowledge. Since the first space launch, different countries and space agencies have been engaged in space exploration focusing on joint human and robotic missions to destinations such as Mars and other destinations that are beyond the solar system.

According to NASA (n.d.), today's space exploration extends to over thirty-six thousand kilometers $(36,000)$ kilometers from the Earth's surface. The exploration includes important technologies such as imaging satellites, global positioning satellites and satellites' communication technologies, which are integral part of the world's economy. Such technologies would not be available today if not for intensive research, development of vast investment in technological innovations and development of enabling technologies by space agencies like the National Aeronautics and Space Administration (NASA) and other government agencies across the developed countries.

Emerging technologies such as Artificial Intelligence, Cloud Computing, and Advanced Data Analysis are playing an important role in the development of powerful space exploration systems, including launch vehicles and satellites. Therefore, this report explores how space computation sciences leverage these technologies to power innovation in the sphere of space technologies.

\section{Research Methodology}

This research uses a qualitative methodology. The methodology is based on the analysis of research papers, articles and industry publications related to space technologies. The main sources used are journals, articles, whitepapers, and industry publications that explore how Artificial Intelligence, Advanced Data Analytics, and Cloud Computing can be used to power innovation in the sphere of space technologies. 


\section{LITERATURE REVIEW}

\section{How technology has transformed space sciences}

2020 marks the $51^{\text {st }}$ year since the Apollo landed on the moon in 1969. The landing was enabled by extraordinary acceleration of space technologies. Within a short period of time before the 1969 moon mission, space engineers had mastered various technologies including space operations, rocket propulsion and on-board computing. The research during that time had unlimited budget. Since those days of heroic moon landing endeavors, space technologies and space sciences in general have developed into interconnected technologies provide the ability to carry out new exciting space missions. However, according to Donepudi (2017), although many have ventured into space exploration since the Apollo Mission, all they have achieved is to circle the Earth in space stations. The development of space shuttles has been less cost-effective. Despite the higher cost and other challenges such as failure of space missions, the development of space technologies has grown significantly.

Today, the earth depends space technologies to orbit satellites around the earth. The satellites play roles such as communication, monitoring of the environment, forecasting of weather and surveillance activities. So far, many nations, not just the developed countries, undertake different magnitudes of space projects. Much of the space projects involve spacecraft which are of course expensive. But the rapid advances in technology miniaturization and computing power have enabled the development of cheaper space crafts. Besides space crafts, space telescopes have been essential in space exploration. There are many space telescopes in the space that beam back data from inaccessible parts of cosmos, in wavebands that may include gamma rays, $x$-rays and ultra-violet rays that can be seen from ground. Such space telescopic observations have enabled the revelation of new cosmic phenomena.

\section{Technology miniaturization}

Due to technology miniaturization, technological devices around the globe have been decreasing in size. About a decade ago, many offices around the world used to be filled with desktop computers. Today, offices do not need those desktop computers since they can rely on ultrathin laptops and mobile phones to stay connected.

In the past few years, satellites and other geospatial equipment have been able to reduce in size significantly. Before miniaturization of technology, satellites and launch vehicles' development used to be costly, especially for large larger space ships. With technology miniaturization, the development of satellites and launch vehicles has become cheaper. For example, according to Donepudi (2017), miniaturization has made it easier to develop space crafts of smaller sizes, such as 100 kilogram satellites used in disaster monitoring. However, the small $100 \mathrm{~kg}$ satellites do not work independently, but in groups known as the Disaster Monitoring Constellation. Moreover, there are satellites with fewer kilograms that can carry different payloads. Such satellites can be used in the observation of the earth or in conducting low cost experiments, since the small satellites can be launched alongside bigger satellites as secondary payloads.

According to Donepudi (2017), issues such as mass have always held the space industry hostage considering the large high cost of getting large masses into orbit. Today, there are standard CubeSats with sizes of about 30 cubic centimeters, 60 cubic centimeters, and 100 cubic centimeters that are cheaper to put in orbit. These small satellites have significantly reduced the historical high costs of satellites and launch vehicles development. However, Donepudi (2015) notes that volume reduction can be problematic. It leads to tighter packing electronics when building satellites and launch vehicles. This miniaturization contributes to greater thermal management challenges which were not common in large spaceships whose components were well-spread, thus distributing the heat generated. However, heating challenges in smaller satellites can be solved by integrating Thermal Interface Material than can spread heat from the satellite's core to its exterior parts that can dissipate heat. This improves heat management.

\section{REFERENCES}

Donepudi, P. K. (2015). Crossing Point of Artificial Intelligence in Cybersecurity. American Journal of Trade and Policy, 2(3), 121-128. https://doi.org/10.18034/ajtp.v2i3.493

Donepudi, P. K. (2016). Influence of Cloud Computing in Business: Are They Robust?. Asian Journal of Applied Science and Engineering, 5(3), 193-196. http://doi.org/10.5281/zenodo.4110309

Donepudi, P. K. (2017). AI and Machine Learning in Banking: A Systematic Literature Review. Asian Journal of Applied Science and Engineering, 6(3), 157-162. http://doi.org/10.5281/zenodo.4109672

$$
--0 \text {-- }
$$

